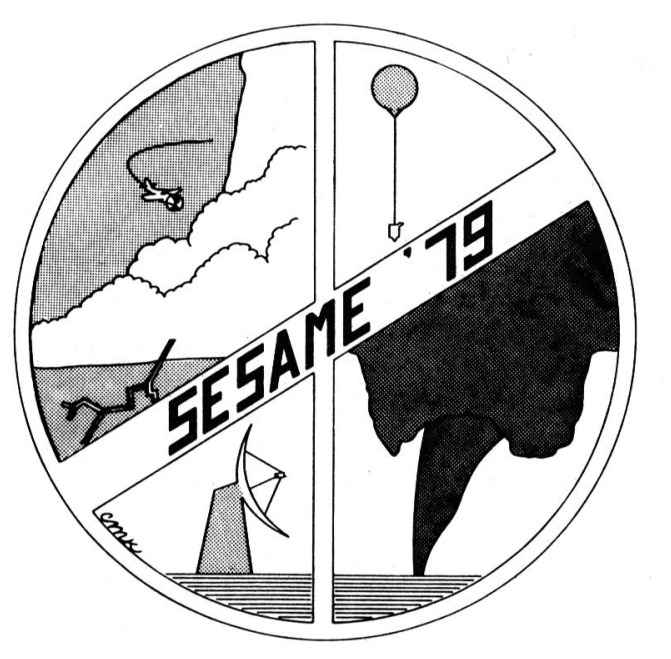

SESAME HEWS

No. 11

January 1983

A series of informative contributions concerning the SESAME project and its 1979 field program, supported by the National Oceanic and Atmospheric Administration, the National Aeronautics and Space Administration, the National Science Foundation, and others. Prospective contributions should be sent to Professor Frederick Sanders, Department of Meteorology, Massachusetts Institute of Technology, Cambridge, Mass. 02139.

\title{
Mesoscale Analysis of Pressure and Precipitation Patterns during AVE-SESAME 1979, 10-11 April
}

\author{
Dayton G. Vincent and Jeffrey H. Homan ${ }^{1}$ \\ Department of Geosciences, Purdue University, W. Lafayette, Ind. 47907
}

\begin{abstract}
A mesoscale analysis of hourly surface data of pressure and precipitation is presented for the case of 10-11 April, during AVE-SESAME 1979. Barograph traces also are used in the analysis. Three distinct pressure waves traveling northeastward across Oklahoma and Missouri are found to be well correlated with thunderstorm activity and heavy rainfall amounts. Wave speeds appeared to propagate at approximately $25 \mathrm{~m} \cdot \mathrm{s}^{-1}$ and to have amplitudes ranging from 2 to $6 \mathrm{mb}$. The average time elapsed between successive wave passages at a particular station was $4 \mathrm{~h}$. A ridge of high pressure passed a station about one hour after heavy precipitation had occurred.
\end{abstract}

\section{Introduction}

During the afternoon and evening of 10 April 1979, a series of thunderstorms, many severe, developed over Texas and Oklahoma. Included among the severe storms was the Red River Valley tornado outbreak, which contained the deadly Wichita Falls tornado. Throughout the evening and early morning hours of 11 April, thunderstorms and heavy precipitation continued to propagate from Texas and Oklahoma

\footnotetext{
${ }^{1}$ Current affiliation: General Software Corporation, 8401 Corporate Dr., Landover, Md. 20785.

(c) 1983 American Meteorological Society
}

toward the northeast. Of particular interest in the present paper is the relationship that occurs between the precipitation patterns and pressure distributions.

A mesoscale analysis of pressure and precipitation is presented, based primarily on hourly observations. Surface pressure data were obtained from the National Weather Service 604 teletypewriter circuit. These data were kindly provided to us by Grant Darkow of the University of Missouri. An example of the surface station network is given in Fig. 1. Barograph traces, purchased from the National Climatic Center (NCC) in Asheville, N. C., were used at selected stations to complement our analysis of hourly pressure data. Hourly precipitation data also were purchased from NCC.

\section{Analyses and discussion}

\section{a. Mesoscale pressure patterns}

Figure 2 shows surface pressure charts for 2000 and 2200 GMT 10 April and for 0000, 0200, 0400, and 0600 GMT 11 April. In addition to the main low pressure system over Colorado, two distinct mesoscale low pressure centers are evident. The first mesolow developed to the west of Childress, Tex., (CDS in Fig. 1) between 1900 and 2000 GMT and is identified easily on the 2000 GMT chart. It moved slowly eastward toward the Red River Valley and intensified between 2000 and $2200 \mathrm{GMT}$. The lifetime of the system was approximately $7 \mathrm{~h}$ 


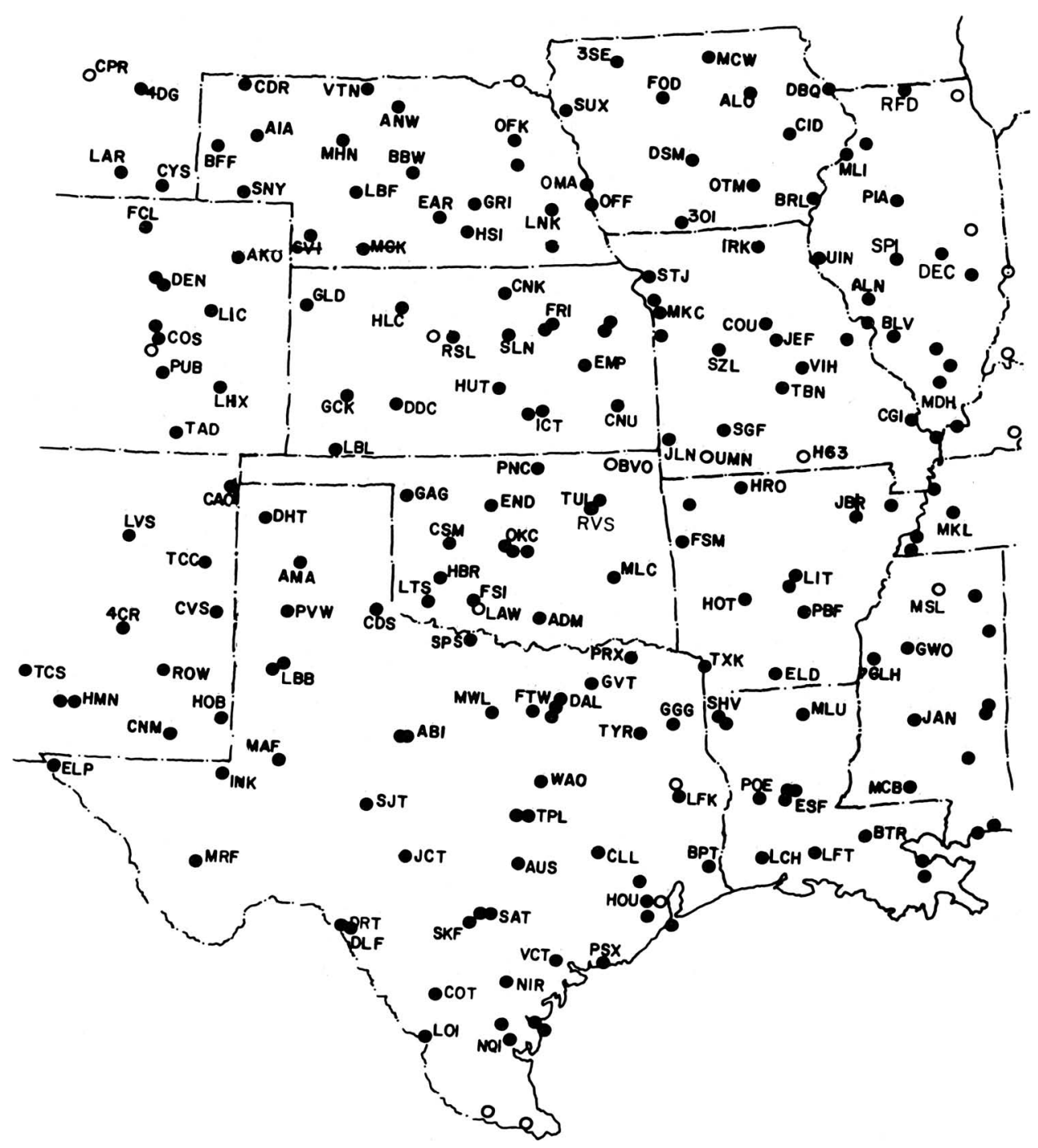

FIG. 1. Surface station network for 0000 GMT 11 April 1979. Black circles represent stations for which data were available.

and the largest pressure falls occurred in southwestern Oklahoma about $3 \mathrm{~h}$ before the Red River Valley tornado outbreak. The second mesolow developed in the San AngeloAbilene, Texas, area between 0100 and 0200 GMT 11 April and can be seen on the 0200 GMT chart. Its lifetime was much shorter and, as was the case for the first mesolow, provided a trigger for a second severe weather outbreak in northcentral Texas. A detailed discussion of the thermodynamic, moisture, and kinematic features of the surface circulation in relation to these mesolows and severe weather outbreaks is given by Homan and Vincent (1982).

Figure 2 also suggests that wave perturbations were occurring in the pressure field as early as 0000 GMT 11 April. To examine this feature further, we analyzed pressure tendency charts for each hour. Figure 3 shows an example for the period 0100-0200 GMT 11 April. The pressure perturbations appear to occur in high-low couplets along a line oriented southwest-northeast from southwestern Oklahoma to northern Missouri. This line, which is shown in Fig. 5, also was located along the approximate position of maximum thunderstorm activity and heavy precipitation that took place during the period 2100 GMT 10 April-1000 GMT 11 April. Barograph traces at selected stations along the line are shown in Fig. 4. Three separate mesoscale waves were identified. Each wave originated in central Oklahoma and traveled northeastward into Missouri. The passage of a pressure surge at a station was well correlated with the occurrence of thunderstorms. The amplitude of a surge ranged from 2 to $6 \mathrm{mb}$. A spacetime cross section of surface pressure along this line, based on hourly reports, is shown in Fig. 5. The three wave packets of alternating trough/ridge lines show reasonably good temporal and spatial continuity and verify that mesoscale pressure waves did propagate from central Oklahoma to northern Missouri during the evening and morning hours of 10-11 April.

\section{b. Mesoscale precipitation patterns}

Subjectively analyzed precipitation charts for 1800 and 2100 

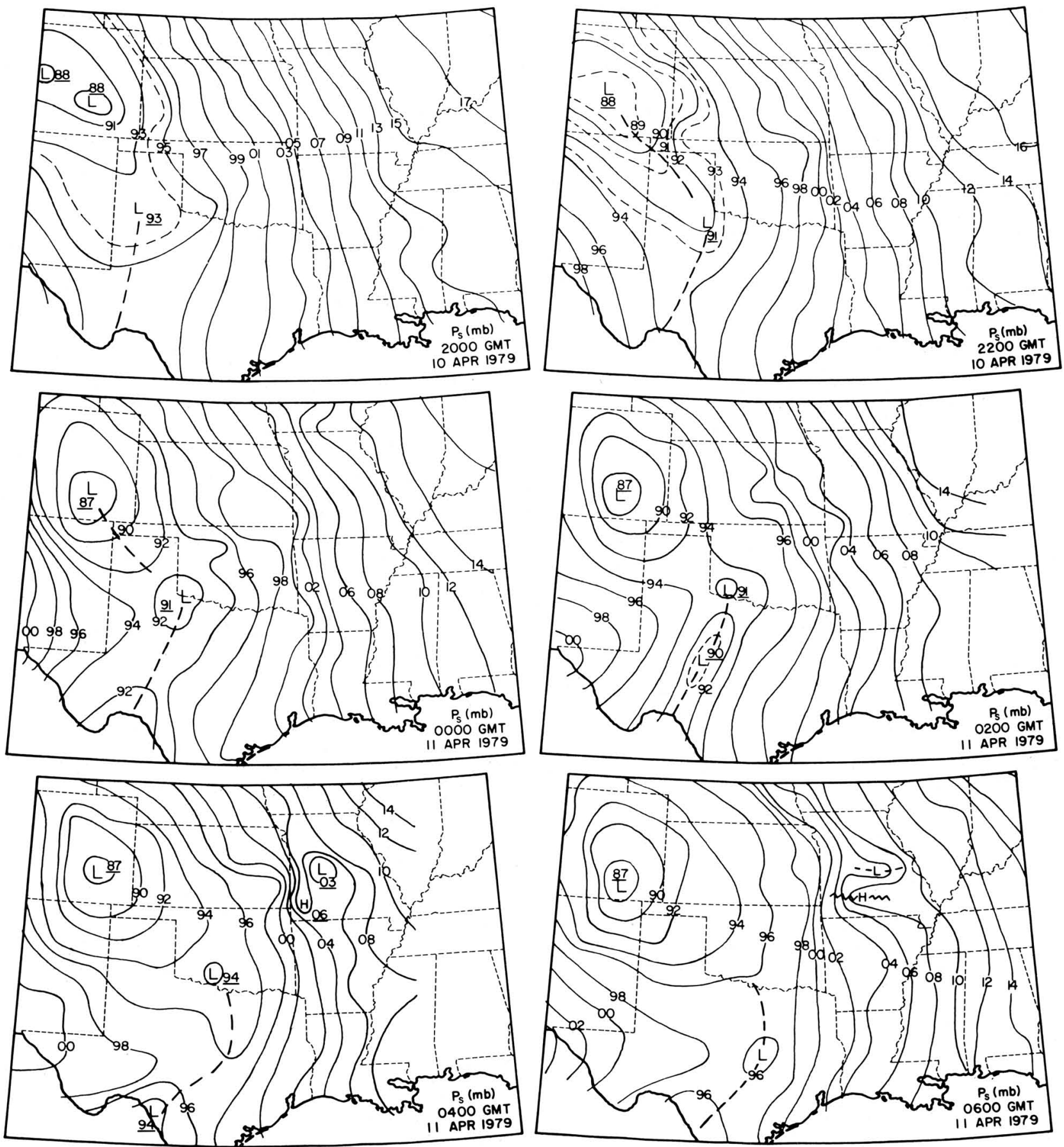

FIG. 2. Surface pressure analyses in millibars for 2000 GMT and 2200 GMT 10 April, and for 0000 GMT, 0200 GMT, 0400 GMT, and 0600 GMT 11 April 1979.

GMT 10 April and for 0000, 0300, 0600, and 0900 GMT 11 April are shown in Fig. 6. All rainfall amounts were linearly averaged in a one degree latitude-longitude square, then averaged over a $3 \mathrm{~h}$ period that began one hour before each indicated map time. Thus, a precipitation pattern represents a smoothed analysis of the mesoscale rainfall distribution. Prior to 1800 GMT 10 April, precipitation was widely scattered and light. At 1800 GMT there were two bands of rain, one in southwestern Oklahoma and the other stretching from central Texas to southern Oklahoma. By 2100 GMT, the only area with significant rain was southwestern Oklahoma, where rates had increased threefold since 1800 GMT. The area of heavy precipitation is seen to spread northeastward at each subsequent map time and, although rates decrease slightly after $2100 \mathrm{GMT}$, the area occupied by rain increases.

A space-time cross section of hourly rainfall amounts along the same line as for pressure is given in Fig. 7. It shows that three distinct bands of heavy precipitation, with lighter 


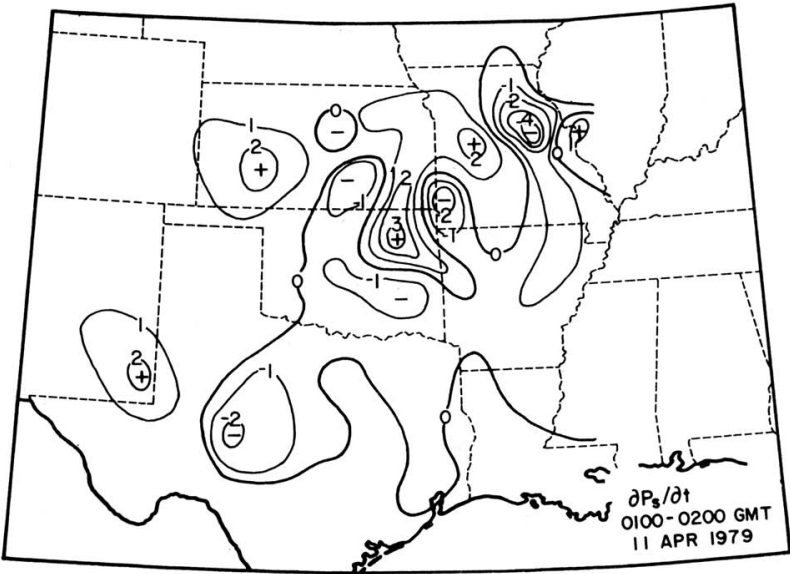

FIG. 3. One-hour pressure tendency chart in millibars per hour for 0100-0200 GMT 11 April 1979.

or no precipitation in between, propagated from southwestern Oklahoma to northern Missouri during the analysis period. The heaviest precipitation generally occurred in conjunction with thunderstorms. Maximum values are higher than those shown in Fig. 6, since values in Fig. 7 have not been time- or space-averaged.

\section{c. Pressure-precipitation relationship}

Figure 8 shows axes of maximum (minimum) precipitation and high (low) pressure ridges (troughs) taken from Figs. 5 and 7. In general, a ridge (trough) of high (low) pressure propagated past an individual location about one hour after heavy (little or no) precipitation had occurred. This was par-

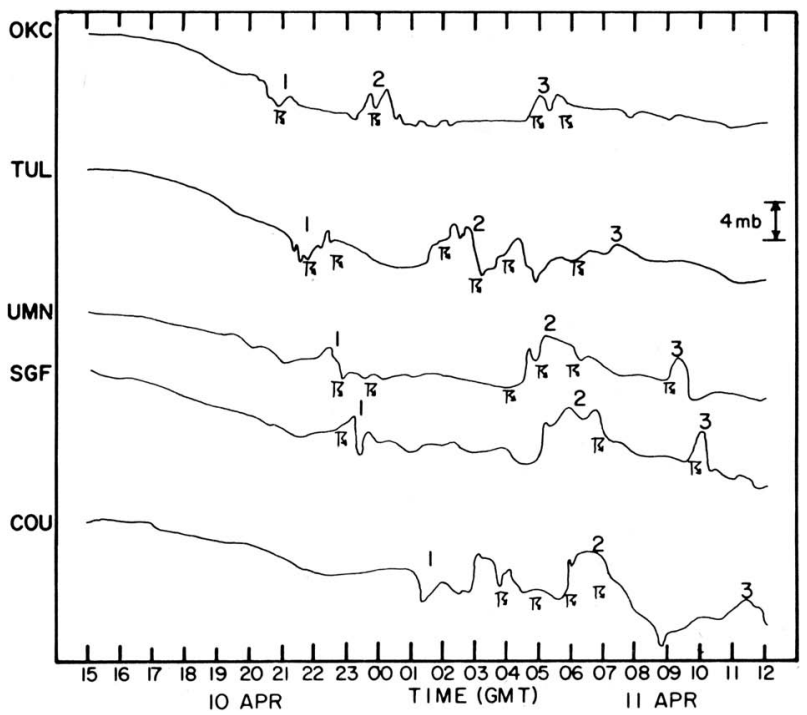

FIG. 4. Barograph traces for Oklahoma City, Okla. (OKC), Tulsa, Okla. (TUL), Monnet, Mo. (UMN), Springfield, Mo. (SGF), and Columbia, Mo. (COU). Thunderstorms are superimposed from hourly surface data. ticularly true in Oklahoma. Thus it appears, as suggested by Fujita et al. (1956), that high pressure surges (mesohighs) are a result of convection rather than a cause of it. The apparent reversal of the pressure-precipitation relation as the storms approached central Missouri may have been due to the fact that they were no longer propagating along the cross-sectional line, or perhaps the higher elevations in the Missouri Ozarks region were altering the flow pattern.

a
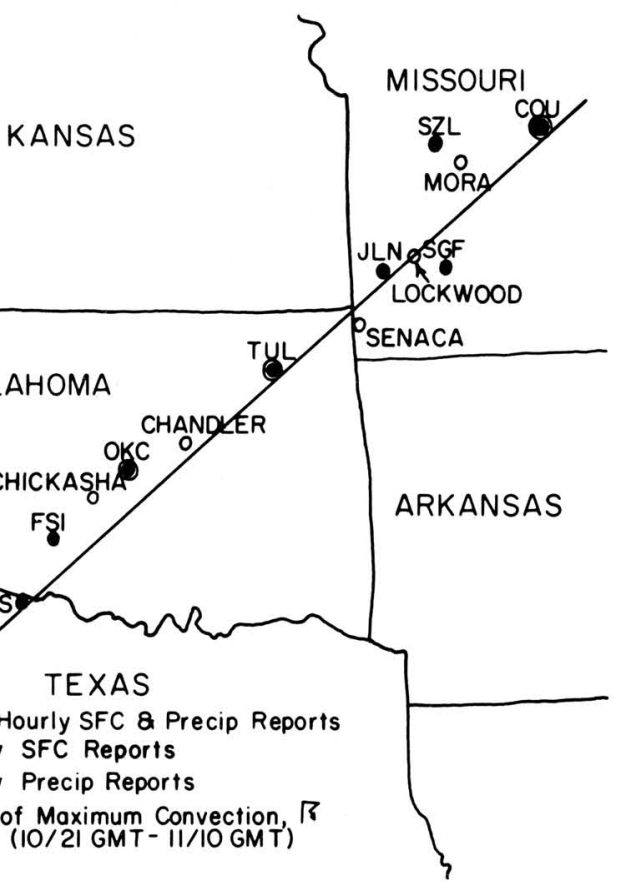

b

MSL PRESSURE (mb) Based on Hourly Surface Data --Trough mM Ridge

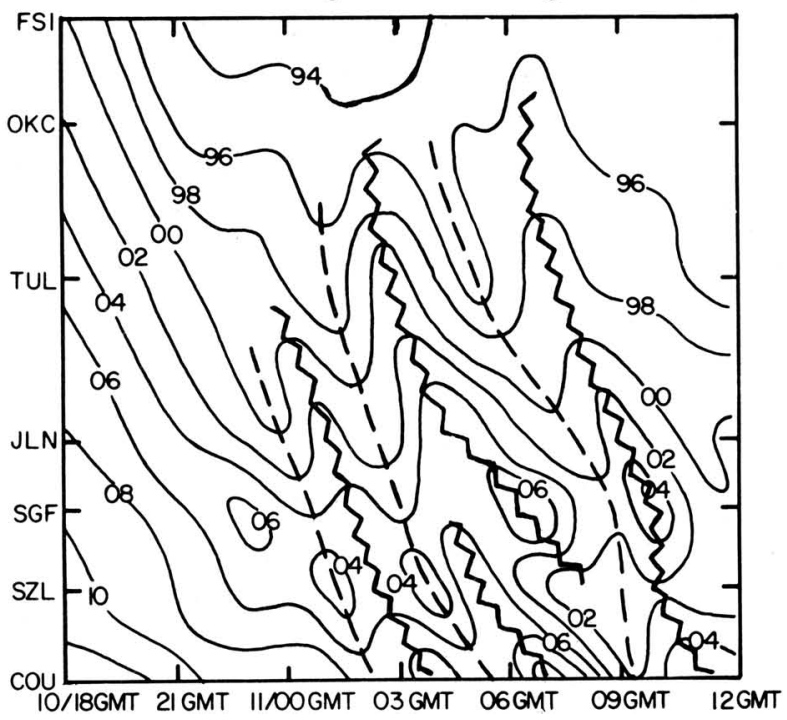

FIG. 5. a) Stations used in cross-sectional analyses of pressure and precipitation, and b) space-time cross section of surface pressure in millibars based on hourly data along the mean path of maximum convection 

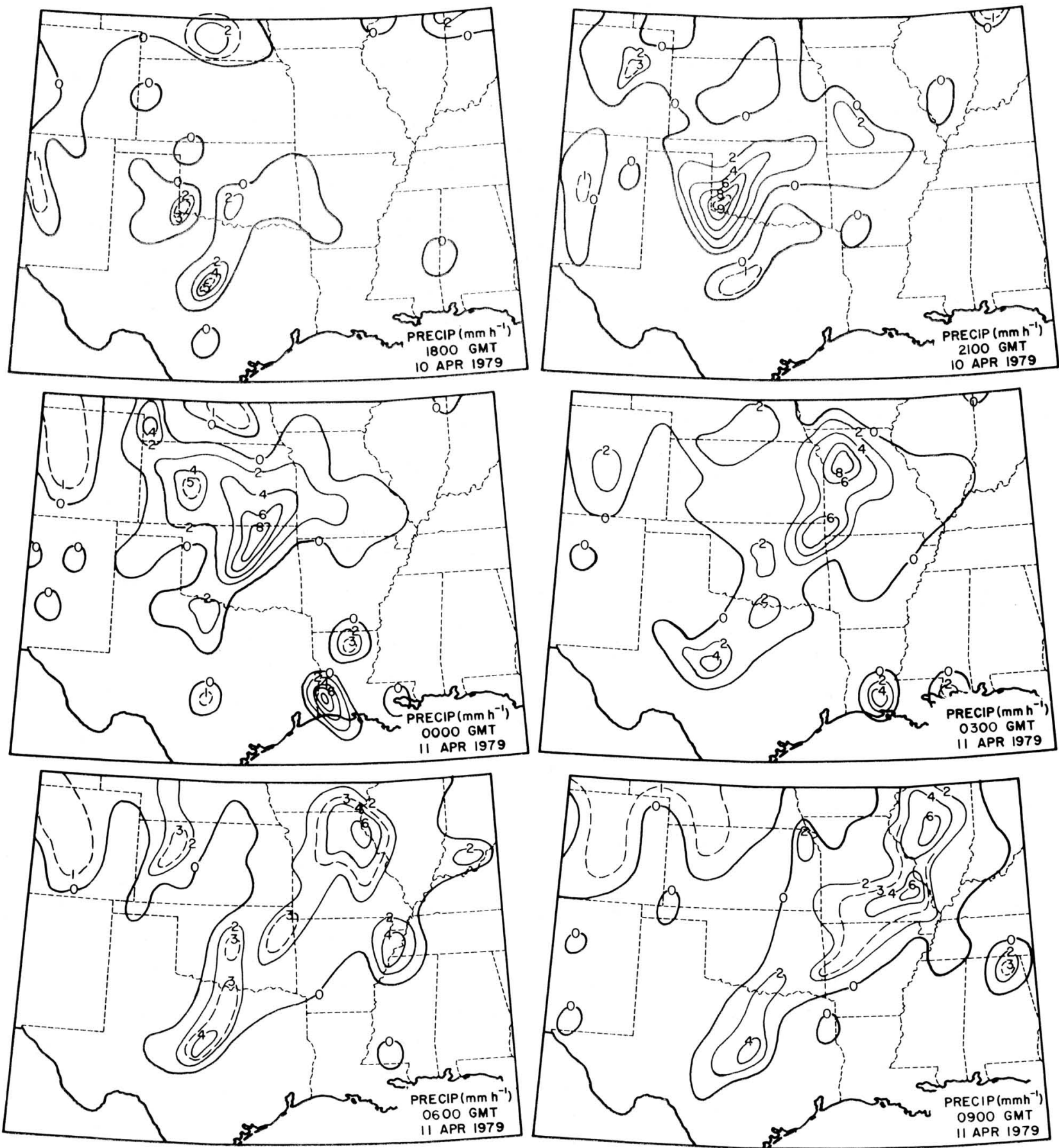

FIG. 6. Precipitation rates in $\mathrm{mm} \mathrm{h}^{-1}$ for $1800 \mathrm{GMT}$ and $2100 \mathrm{GMT} 10 \mathrm{April}$, and for $0000 \mathrm{GMT}$, 0300 GMT, 0600 GMT, and 0900 GMT 11 April 1979. See text for details of calculation.

The time elapsed between two ridges or troughs of pressure (i.e., one wave) passing a fixed location was approximately $4 \mathrm{~h}$. The average distance between two positive or two negative centers of hourly pressure tendency along the crosssectional line (Fig. 3) was about $350 \mathrm{~km}$. The same trend occurs for maximums and minimums of precipitation. Therefore, the mean propagation speed of the thunderstorms and associated mesoscale pressure waves from southwest to northeast was about $25 \mathrm{~m} \cdot \mathrm{s}^{-1}$.

\section{Concluding remarks}

A number of studies have been conducted in which propagating mesoscale pressure waves were examined (e.g., Bosart and Cussens, 1973; Eom, 1975; Uccellini, 1975; Miller and Sanders, 1980). Of these, the latter two are in agreement with the present study in that thunderstorms and heavy precipitation are well correlated with the passage of high pressure ridges. We suspect, as do the authors just mentioned, that our 


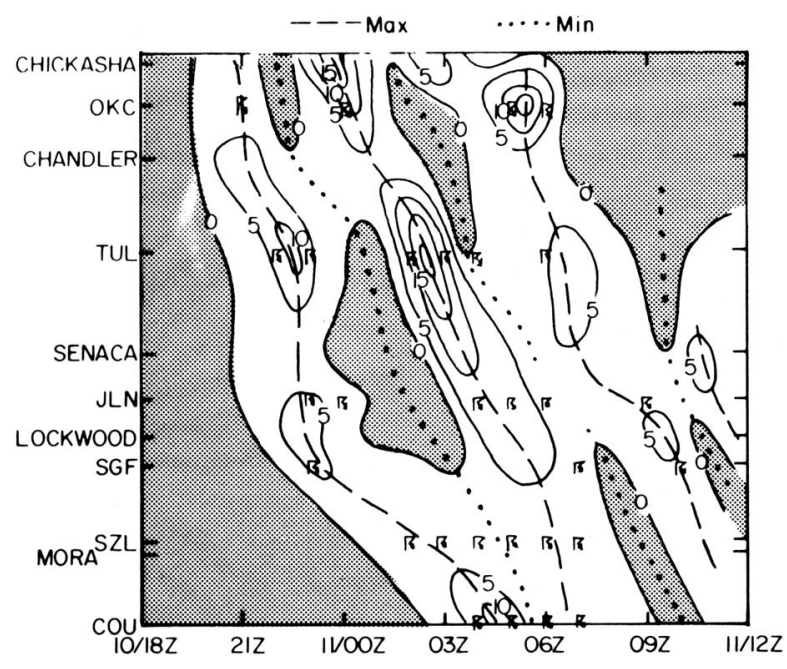

FIG. 7. Space-time cross section of hourly precipitation amounts in millimeters, based on reports along the mean path of maximum convection (see Fig. 5a).
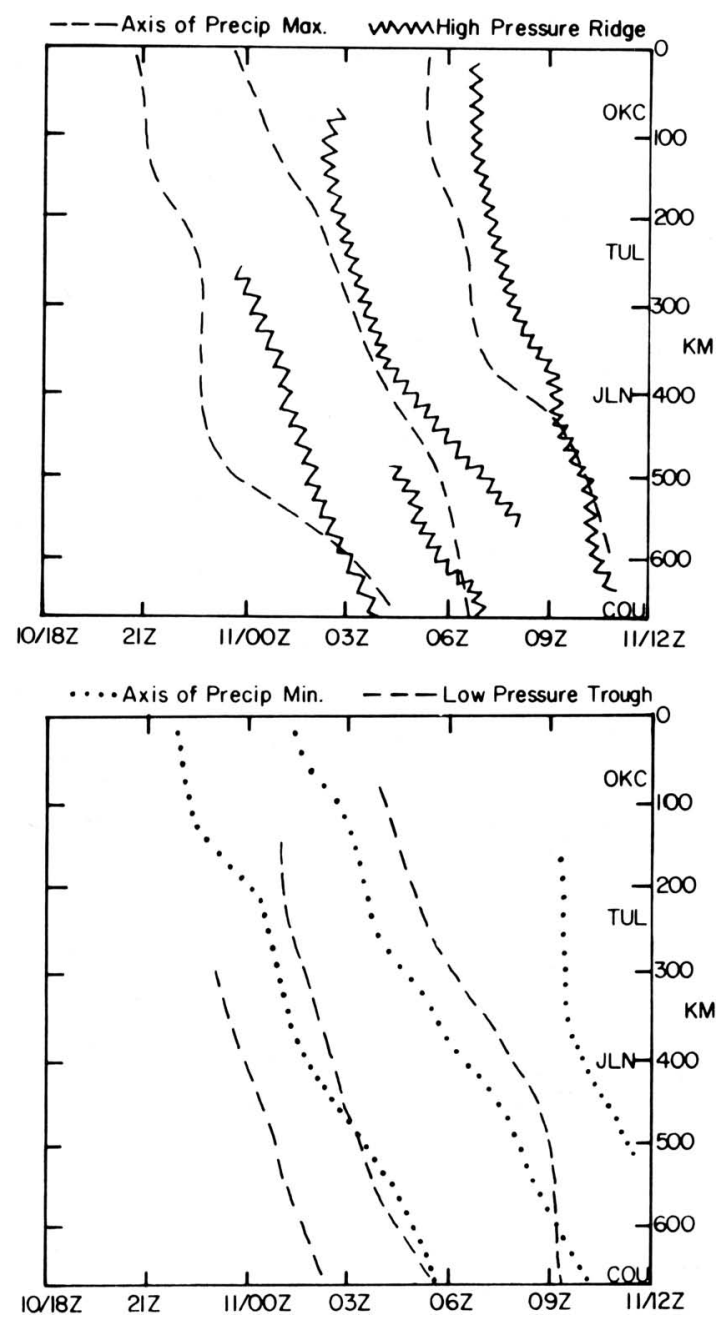

FIG. 8. Cross sections showing axes of maximum precipitation and high pressure ridges (top) and minimum or no precipitation and low pressure troughs (bottom), taken from Figs. 5 and 7. waves are a type of gravity wave. Uccellini, for example, argued that gravity waves are a precursor to storm development. In the present case, it is unclear whether gravity waves initiated thunderstorms or vice versa. In the coming months we plan to investigate further the link between thunderstorms and wave propagation. The uniqueness of upper-air data taken during SESAME 1979 (i.e., data from twice as many stations as usual and $3 \mathrm{~h}$ soundings) and a more detailed analysis of surface data (including barograph data) should help us in this investigation. Currently, we have an objectively analyzed, gridded set of upper-air data for every three hours from 1200 GMT 10 April to 0300 GMT 11 April. In the near future we plan to complete this data set by finishing the gridding of the remaining three analysis times: 0600, 0900, and 1200 GMT 11 April. At that time we shall continue our study of the relationship between pressure and precipitation patterns during 10-11 April 1979. An observational and theoretical approach, similar to that conducted by Uccellini (1975), seems to be a feasible one to try.

Acknowledgments. The authors express their sincere gratitude to Grant Darkow of the University of Missouri for supplying them with the surface data that made the analysis possible. They also thank Richard Fulton for plotting the data and drafting the figures, and Tanya Care for typing the manuscript. The research was supported under NSF Grant No. ATM80-16169 awarded to Purdue University by the Meteorology Program, Division of Atmospheric Sciences, National Science Foundation.

\section{References}

Bosart, L. F., and J. P. Cussens, 1973: Gravity wave phenomena accompanying East Coast cyclongenesis. Mon. Wea. Rev., 101, 446-454.

Eom, J., 1975: Analysis of the internal gravity wave occurrence of April 19, 1970 in the Midwest. Mon. Wea. Rev., 103, 217-226.

Fujita, T., H. Newstein, and M. Tepper, 1956: Mesoanalysis: An important scale in the analysis of weather data. Weather Bureau Res. Pap. 39, U.S. Department of Commerce, Government Printing Office, Washington, D.C., 83 pp.

Homan, J. H., and D. G. Vincent, 1982: Mesoanalysis of the severe storm outbreak of 10-11 April 1979. (Submitted to Mon. Wea. Rev.)

Miller, D. A., and F. Sanders, 1980: Mesoscale conditions for the severe convection of 3 April 1974 in the east-central United States. J. Atmos. Sci., 37, 1041-1055.

Uccellini, L. W., 1975: A case study of apparent gravity wave initiation of severe convective storms. Mon. Wea. Rev., 103, 497-513. 